\title{
Towards Excellence Organization Founded in Human Identity
}

\author{
Alejandro Sanchez Garcia* \\ University Of Guanajuato, Guanajuato, Mexico
}

\begin{abstract}
The development of management thinking, has focused on the study and emphasis of the organizations, that is, single approach by specializing in specific segments, whether the task, structure, strategy, and very sparingly, It has attended the study of shared organizational values and human identity; Therefore, these approaches have been maximized in order to seek more effective solutions to organizational problems; Thus, the demands and pressures that are subject organizations of the future, if their senior executives aim to achieve more efficient management of resources for the generation of products and services of higher value, which allows a higher yield for investors and a better quality of life for workers, it is necessary to formulate and implement sophisticated new methods, tools, instruments and management systems that are centered on people, this is their shared values, to achieve organizations founded on human identity.
\end{abstract}

Keywords: Organization; Excellence; Rationality; Shared values; Human identity

\section{Introduction}

Much has been discussed about the organizations. Etzioni mentioned us in a very timely manner that "... born within organizations, we are educated by them and most of us consume much of our lives working for organizations. We use much of our free time spent playing, and praying in organizations. Most of us will die in an organization, when the day of the funeral arrives the largest organization of all-the state must grant official permission...” [1].

Throughout the development of management thinking several authors have focused on the study and emphasis of the organizations, maximizing this approach in order to seek more effective solutions to organizational problems.

Since Taylor in the late nineteenth century and early twentieth century, raising the scientific management with emphasis on the task or work processes; focusing on streamlining the operational work; the classical and neoclassical theories, Bureaucratic Weberian theory whose emphasis lies in the structure of organizations focusing on the general principles of mechanistic or formal organization; Theories of human relations, organizational behavior and organizational development with emphasis on people and informal approaches main elements of organizations: motivation, leadership, communication and group dynamics; structuralist school until the end of the fifties, is emphatic in studying environmental organizations, focusing on the organization as an open system; all representative of the always constant effort to solve the new problems of the hard and formal part (called cold side), and the soft and informal part of the organizations (also called warm side) allow us to draw a number of strategic targeting processes, structures or people in organizations (Figure 1).

\section{Developing}

Difficult to define what an "Organization" in one word. Then we refer the most representative definitions.

Philip Selznick says that “... the formal organization is the structural expression of rational action” [2].

Chester Barnard, "refers to a formal organization is a system of consciously coordinated activities or forces of two or more people" [3].

David Silverman states that "organizations are social institutions with certain special characteristics: they are consciously created in a given time; its founders have given goals that are often important, especially as legitimizing symbols; the relationship between its members and the source of legitimate authority is relatively well defined, though often the latter is subject to discussion and a planned change" (Silverman: 1971:47).

Dwight Waldo argues that “...the organization can be defined as authoritarian structure and routine personal relationships in an administrative system" [4].

Worth mentioning that at the end of 1970 was introduced, the 7-S framework by consultants McKinsey in New York, this model was a milestone in thinking about organizational effectiveness. A previous approach was to analyze managers within organizations in the structure, who does what, who reports to whom, and similar issues. As organizations grew in size and complexity, the most critical question became the coordination problem. (Consulted on http://www. mckinsey.com/insights/strategy/enduring_ideas_the_7-s_framework: [Recovery date: 10/11/2015] (Figure 2).

Here the explanation model: The McKinsey $7 \mathrm{~S}$ is a model that combines the 7 basic factors in any organizational structure. Usually to assess whether the implementation of any strategy in the organization would be aligned with those factors. If not it would be necessary to reconsider all or part of the strategy.

In organizations there are two types of elements:

- Emotional: Shared values, skills or competencies of employees, corporate culture, staff.

- Rational: Strategy, Structure, Systems Work.

In this sense, the model of Mckinsey theorizing we can say that human identity is referred to light factors, soft factors in organizations:

*Corresponding author: Garcia AS, University Of Guanajuato, Guanajuato, Mexico, Tel: +5214772674900; E-mail: asanchezg.gcg@gmail.com

Received October 31, 2015; Accepted January 27, 2016; Published January 29 2016

Citation: Garcia AS (2016) Towards Excellence Organization Founded in Human Identity. Review Pub Administration Manag 4: 181. doi:10.4172/23157844.1000181

Copyright: $\odot 2016$ Garcia AS. This is an open-access article distributed under the terms of the Creative Commons Attribution License, which permits unrestricted use, distribution, and reproduction in any medium, provided the original author and source are credited. 


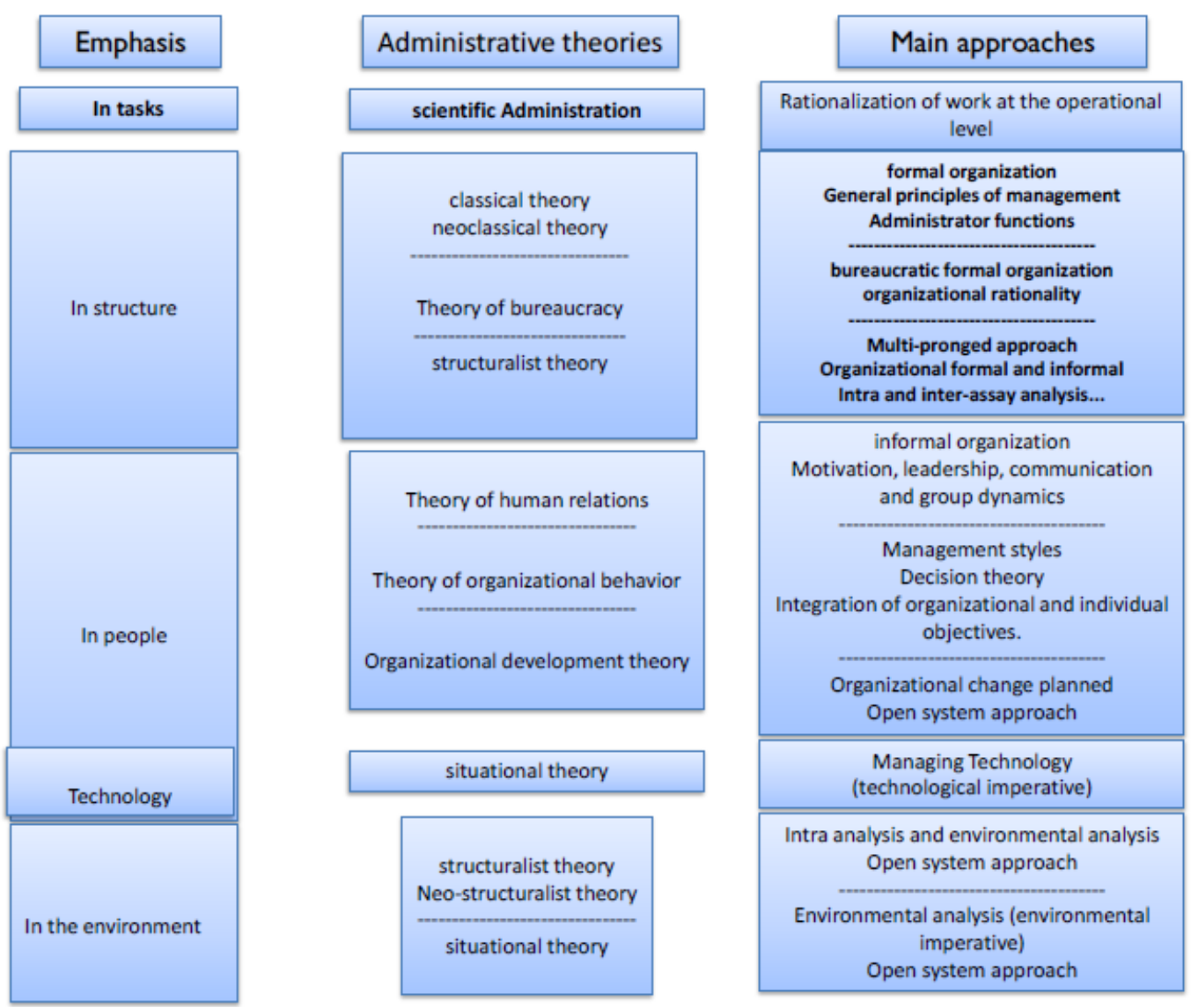

Figure 1: Approach to management theories in organizations.

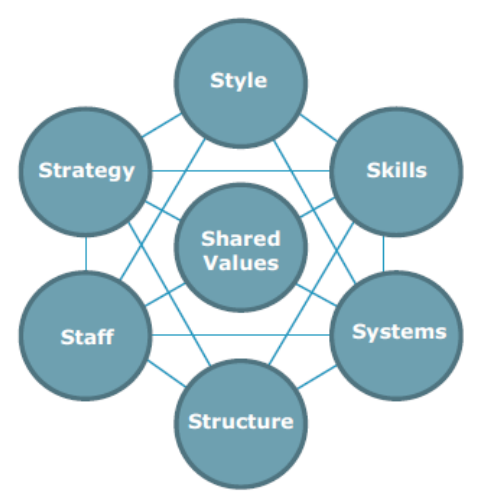

Figure 2: Model diagram 7’S McKinsey.

Shared values, skills or competencies of employees, Organizational culture, Staff [5].

Around the concept of Human identity, Erikson described it "as a sense of psychosocial well-being." That is feeling good about his own body, a sense of knowing where you are going, as well as internal security of recognition provided for those who are important [6].

In this sense, the demand of mankind for "excellence" in the decade of the seventies and eighties, oriented organizations to rethink their customer objectives and productivity, but neglecting the emotional sphere of organizations: their identity.
The classic model is focused on finding and building a purely rational model. As effectively they argue "... well-trained professional managers can manage anything. Search an impartial and analytical justification for all decisions. It's sufficiently to be dangerously correct and erroneous can be argued that it has deviated us from the right path" [7].

In this sense, the excellence of the manager who manages the organization is focused on the "objective", that is, productivity and results obtained driving action, autonomy and spirit of entrepreneurial service, flat levels and lax attitudes and intense. These can be broadly the features of rational organizations.

Commitment to the above, it has neglected the "irrational" aspect of organizations, same as is represented by their "instincts", "values" and "ideal". The "manager" or "manager of excellence" focusing only on rationality, result in high costs, not only purely economic, but those related to the loss of the "identity" of the organization that says 'excellent'.

In this context, organizations have a significant impact on the objectives of society, in their internal processes and their environment, in their organizational interdependence, but especially in matters of content, that is, on the concerns and approaches "ethical "or" moral "individual and group.

In recent years, a multitude of initiatives by non-state actors have tried to incorporate labor standards, human rights, environmental protection and social values of the global economy to the field of 
study of organizations, in order to ennoble, because it is undoubtedly the human element, their feelings, their thinking and their actions; in short, intangible real engines of organizations.

Also, some organizations have gone beyond their limits in terms of its supply chain. We find in them ethical codes, ethical sourcing guidelines and social reporting; environmental sustainability; participation in certification programs, among other no less important. This presents us certainly true desirability of producing excellence in organizations, should consider the "identity of the people" as an integrated set of values, behaviors and instincts together for the same ideological foundations are giving pattern to a relationship between the rational dimension and the ethical dimension, allowing us to build organizations based on human identity.

Examples contrary to the above, “... we find between various multinational ... All have in common the fact that placed the principle of excellence [rationalist model] and perfection in front of their value system ... it could be debated at length about whether the ethical principles that drive these companies are an ideological disguise of a yearning for power and competitive capitalism, or if you really stem from a moral concern. In any case, what matters is the indissoluble union between ethics and economic dimension ..." [8].

Thus we see the need to return to Toral the inside of the human being in order to solve the most pressing problems of contemporary organizations, same as in most occasions, are the result of mishandling or treatment of relations interpersonal and implicit content thereof: psychic representations, values formation and ethical behaviour of people.

As Edgar Morin aptly says "The human unity is strongly affirmed, but no less strongly human diversity, and these at all levels, biological, individual and cultural.

... The individual himself is a multiple; the unit is conceived not only on genetic, physiological, cerebral base, but also from ... the notion of subject that particularly involves a dual principle of exclusion and inclusion for understanding both the self-centeredness, and intersubjectivity altruism" [9].

\section{Conclusions}

In this situation, the organization of excellence should not only base its findings on the rational dimension of the CEO (Chief Executive Officer), but turn on the inside dimension of the person, instinctive and psychological, if desired build a model whose center imputation decisions to the identity of the human person, it will determine the form of "being" in organizations.

The success of public or private organizations depends on the ways of thinking and analyzing by its members, and it is this aspect which we must focus, in the first instance, our effort. While the human aspect always part of the management companies and management entities or public organizations, concepts and paradigms existing until recently would not assigned to it a profile consistent with current needs.

"The humanistic approach promotes a real conceptual revolution in management theory: if before the emphasis was on task (by the scientific administration) and organizational structure (by the classical theory of administration), now It does in people who work or participate in organizations. In the humanistic approach, concerns about the machine and method of work, formal organization and administration principles applicable to the organizational aspects yield the priority concern for man and his social group: the technical and formal aspects is passed to the psychological and sociological aspects. (Theory of Human Relations at Open University, Adult study Program in Bachelors, Masters and $\mathrm{PhD}$ ) [10].

The leader, manager or executive, should foster a sense of identity and belonging among its workers and peers, and to this end, should consider as their principal and ally. For this, the Personnel Management and the Management of Senior Management should expand their spectrum of intervention and promote that value in corporate culture and in their daily work.

The exigencies and pressures that will subject the organizations to more efficient management of resources for the generation of products and services of greater value, enabling a higher return to investors and a better quality of life for workers, practice involves sophisticated new methods, tools, instruments and management systems that are centered on people-based organizations to achieve human identity.

\section{References}

1. Amitai E (1986) Modern Organizations. Academic Press, Mexico.

2. Philip S (1948) Foundations of the Theory of Organizations. American Sociological Review 13(1): 25-35.

3. Chester B (1938) The Functions of the Executive. Harvard University Press, Cambridge.

4. Dwight W (1955) The study of Public Administration. Random House, New York.

5. Enduring Ideas: The 7-S Framework. McKinsey \& Company. Accessed on: 11 February, 2016.

6. Erik E (1959) Theory of Identity Development. OXFORD.

7. Thomas JP, Waterman RH (2000) In Search of Excellence. Lasser Press Mexicana, Mexico.

8. Nicole A, Vincent G (1993) The Cost of Excellence. Polity Press, Barcelona.

9. Edgar M (2003) The method: The humanity of mankind. Chair, Madrid.

10. http://www.elprisma.com/apuntes/administracion_de_empresas/ relacioneshumanas 